\title{
ATIVIDADES INOVATIVAS EM PARQUES TECNOLÓGICOS: UMA ANÁLISE COMPARATIVA DA EXPERIÊNCIA DO NORDESTE BRASILEIRO
}

Raisa Teixeira Santana ${ }^{1}$

Rodrigo Teles Dantas De Oliveira ${ }^{1}$

Iracema Machado De Aragão Gomes ${ }^{1}$ 


\section{ATIVIDADES INOVATIVAS EM PARQUES TECNOLÓGICOS: UMA ANÁLISE COMPARATIVA DA EXPERIÊNCIA DO NORDESTE BRASILEIRO}

\section{RESUMO}

Este artigo tem como objetivo a caracterização dos parques tecnológicos instalados na região Nordeste do Brasil, a descrição dos principais produtos desenvolvidos e a investigação, de forma comparativa, do impacto das atividades inovativas desenvolvidas por essas instituições. Para operacionalizar a pesquisa, que tem natureza descritiva, utilizou-se como instrumento de coleta de dados o questionário semiestrurado, que foi aplicado aos representantes de cada parque tecnológico abordado. Os resultados demonstraram que os parques tecnológicos nordestinos têm natureza e forma jurídica adequada para sua atuação; a maioria encontra-se em busca de conformação estrutural, implantando os elementos necessários às atividades inerentes aos parques tecnológicos. Percebeu-se que os portfólios de produtos concentram-se em tecnologia da informação básica, não havendo inovações revolucionárias no âmbito dos parques analisados. Quanto ao impacto das atividades inovativas, a maioria dos itens abordados foi considerado de alta e média relevância pelo maior número de parques.

Palavras-chave: Parques Tecnológicos. Atividades Inovativas. Pesquisa e Desenvolvimento (P\&D). 


\section{Introdução}

Os parques tecnológicos são espaços que, desde a década de 1990, vêm se transformando em núcleos de referência em atividades inovativas, a partir da colaboração entre atores-chave, como as universidades, institutos de pesquisa e empresas de base tecnológica (Zouain, 2003; Pessôa, Cirani, Silva, \& Rangel, 2012). Nesse contexto de inovação, a Pesquisa e Desenvolvimento (P\&D) de tecnologias relevantes de forma contínua é um fator cada vez mais importante, devido à diminuição do ciclo de vida dos produtos (Chen, Wang, Chang, \& Hung, 2014; Tola \& Contini, 2015; Farré-Perdiger, Sala-Rios, \& Torres-Solé, 2016).

O advento dos parques tecnológicos objetivou desde sempre o fomento à inovação, ao concentrar, no mesmo local, as diferentes atividades e agentes a esta inerentes, dando aos parques um papel relevante no desenvolvimento de novos produtos e serviços. Chen et al. (2014) e Farré-Perdiger et al. (2016) discorrem, nesse sentido, que as inovações surgem por meio das interações entre universidade, empresas e parques tecnológicos, que se coadunam em busca da criação e/ou melhoria de tecnologias.

Existem vários conceitos, bem como terminologias, na literatura, sobre parques tecnológicos. Para fins dessa pesquisa, utilizam-se os conceitos da Associação Nacional de Entidades Promotoras de Empreendimentos Inovadores (ANPROTEC) e da International Association of Science Parks (IASP), órgãos detentores de credibilidade no setor. A ANPROTEC (2016a) traz como características dos parques tecnológicos a sua vinculação aos setores de alta tecnologia e o fato de promoverem a criação de empresas de base tecnológica, independentemente do porte da organização, entre outros.

No âmbito dos parques tecnológicos, as atividades inovativas desempenham importante papel, ao criarem as condições necessárias para sua atuação. Seja na atuação da P\&D ou na aquisição de equipamentos e softwares, as atividades inovativas oportunizam a diferenciação das organizações por meio dos produtos e processos de gestão que alavancam suas atividades comerciais (Kayalar, Çıta, Ergani, \& Aktekin, 2015).

A partir desse contexto, o presente trabalho tem como objetivo a caracterização dos parques tecnológicos instalados na região Nordeste do Brasil, a descrição dos principais produtos desenvolvidos e a investigação, de forma comparativa, do impacto das atividades inovativas desenvolvidas por essas instituições. Nas seções seguintes, há a fundamentação teórica - abordando a inovação e os parques tecnológicos -, a metodologia da pesquisa, a análise dos resultados e, por fim, as considerações finais.

\section{Inovação}

Precursor da discussão acerca das inovações, Schumpeter (1961) afirma que são os novos produtos, métodos de produção ou transporte, mercados e formas de organização industrial que impulsionam a empresa capitalista. Já com relação à classificação das inovações, Von Stamm (2003) pontua que podem ser: a) estruturais: definem a configuração básica dos produtos e processos, estabelecendo os padrões técnicos e de marketing que guiarão os desenvolvimentos subsequentes; b) de nicho de mercado: criam novas oportunidades de mercado mediante o uso da tecnologia existente, conservando e fortalecendo os projetos estabelecidos; c) regulares: compostas por mudanças que emergem de competências técnica e de produção estabelecidas, fortalecendo as habilidades e recursos existentes; d) revolucionárias: 
alteram os padrões de competência técnica e de produção estabelecidos, tornando-os obsoletos, sendo aplicadas a mercados e clientes existentes.

Assim, percebe-se que as inovações ocorrem de várias de formas e Chen et al. (2014) assinalam que determinadas características do mercado, tais como curto ciclo de vida do produto e altas taxas de introdução de novos produtos, colocam a inovação como a chave para a sobrevivência das organizações.

As inovações dificilmente são criadas de modo isolado (Chen et al., 2014). Seguindo essa lógica, as inovações tecnológicas não são dependentes de atividades isoladas dos agentes, mas da dinâmica da troca dos conhecimentos gerados (Farré-Perdiger et al., 2016). Esses autores pontuam que existem evidências de que uma pesquisa básica não é suficiente para promover inovação; logo, a interação entre universidade, empresas e parques tecnológicos possui um papel crucial nessas criações.

Entretanto, inovar não é uma tarefa fácil. O Instituto Brasileiro de Pesquisa e Estatística (IBGE) (2016) elaborou o Relatório de Pesquisa de Inovação (PINTEC), que aborda como obstáculos à inovação: escassez de serviços técnicos, fraca resposta dos consumidores, dificuldade para se adequar a padrões, falta de informação sobre o mercado, falta de pessoal qualificado, rigidez organizacional, escassez de fontes de financiamento, elevados custos da inovação e altos riscos econômicos. Tais fatores devem ser considerados pelos empreendedores ao decidirem o setor de atuação, o público-alvo e os produtos/serviços a serem ofertados.

Pessôa et al. (2012) alertam para o fato de que é preciso saber onde e como inovar. Desidério (2016) discorre sobre as oito áreas promissoras para abrir um negócio do futuro; são elas: fabricação de drones, realidade virtual, inteligência artificial, tecnologia e análise de alimentos, leitura biométrica, detecção de fraude, bem-estar corporativo e materiais de construção sustentáveis. Assim, é possível perceber que os empreendimentos de sucesso provavelmente estarão relacionados com tecnologia de ponta.

\subsection{Atividades Inovativas}

As atividades inovativas podem ser entendidas como ações orientadas ao desenvolvimento e difusão de inovações e são observadas nas organizações que apresentam atividades como: aquisição de máquinas, equipamentos e softwares; treinamento; introdução de inovações tecnológicas no mercado; projetos industriais; aquisição de P\&D externa e aquisição de outros conhecimentos externos (IBGE, 2016). Parolim (2013), por sua vez, pondera que a tecnologia não encerra a caracterização de uma empresa como inovadora: é preciso uma estratégia de gestão atenta à dinâmica do mercado, que possibilite adaptações contínuas para o alcance dos objetivos.

As universidades e demais instituições de pesquisa produzem uma grande variedade de conhecimentos cada vez mais sofisticados, e a tecnologia oriunda dessas pesquisas requer investimentos significativos (Tola \& Contini, 2015). As temáticas que compõem as atividades inovativas na universidade incluem suas divisões estruturais, de pessoal (corpo administrativo, autoridades municipais, empresas, entre outros) e atores-chave que fazem parte do estabelecimento dessas atividades (Glebova, Yasnitskaya, \& Maklakova, 2015).

No âmbito dos parques tecnológicos, Goraczkowska (2014) afirma que a evolução das atividades inovativas é mais visível quando há cooperação entre as empresas localizadas no parque e aquelas que fazem parte da sua cadeia de suprimentos. Estas podem fazer uso das atividades inovativas para se diferenciarem por meio dos produtos, processos de gestão e 
métodos de marketing, aumentando suas atividades comerciais. A inovação é uma ferramenta para as organizações, que gera o aumento da eficiência e do lucro de todo um mercado, seja ele novo ou não (Kayalar et al., 2015).

A difusão da tecnologia é um fator complexo devido à existência de vários processos sociais que podem influenciar o modo pelo qual a inovação se torna parte do dia a dia dos indivíduos, contexto fundamental em que os relacionamentos entre sociedade e tecnologia podem ser analisados (Tola \& Contini, 2015).

Akhmetzianov e Kosachev (2016) citam como medidas das atividades inovativas os gastos com P\&D e o volume de produção dos itens inovadores. Bagheri, Eshtehardi e Goodarzi (2015) tratam da utilização de patentes como um indicador de atividade tecnológica, visto que, por definição, elas estão relacionadas com inovação, além de possuir um padrão que muda lentamente. Albahari, Pérez-Canto, Barge-Gil e Modrego (2016), por sua vez, abordam as patentes como um resultado intermediário, sendo matérias-primas para futuro desenvolvimento.

Com relação ao Brasil, De-Carli, Segatto, Alves e Kuribara (2017) comentam que, entre os anos de 2004 e 2011, houve um aumento no número de patentes registradas, entretanto, nos anos 2012 e 2013, ocorreu um decréscimo nessa evolução. Nesse contexto, se a causa para a diminuição na quantidade de patentes registradas ocorreu em virtude da diminuição das atividades inovativas, os parques tecnológicos devem desenvolver cada vez mais o estímulo à inovação nas organizações que os compõem.

\subsection{Parques Tecnológicos}

Os parques científicos e tecnológicos têm atraído bastante atenção na comunidade científica, e sua relevância nas questões relativas às políticas de tecnologia e inovação tem crescido em vários países, paralelamente ao contexto dos negócios (Albahari et al., 2016; Guadix, Carrillo-Castrillo, Onieva, \& Navascués, 2016).

Löfsten e Lindelöf (2005) explicam que não há um conceito uniforme amplamente aceito para definir os parques tecnológicos. Muitas são as terminologias para caracterizá-los, como Parques de Pesquisa, Parques Tecnológicos, Parques de Negócios, Centros de Inovações, entre outros. Apesar de algumas diferenças operacionais, esses espaços possuem o mesmo objetivo: oferecer um ambiente de criação e desenvolvimento de tecnologia de ponta.

As principais definições dos parques tecnológicos são propostas por entidades especializadas no tema, a exemplo da IASP da ANPROTEC. Esta última apresenta o seguinte conceito para parques tecnológicos:

Um parque tecnológico é um complexo produtivo industrial e de serviços de base científico-tecnológica, planejado, de caráter formal, concentrado e cooperativo, que agrega empresas cuja produção se baseia em pesquisa tecnológica desenvolvida nos centros de $\mathrm{P} \& \mathrm{D}$ vinculados ao parque. Trata-se de um empreendimento promotor da cultura da inovação, da competitividade, do aumento da capacitação empresarial, fundamentado na transferência de conhecimento e tecnologia, com o objetivo de incrementar a produção de riqueza de uma região (ANPROTEC, 2016a, p. 11).

Corroborando o conceito da ANPROTEC (2016a), a IASP (2017) afirma que o principal objetivo dos parques é aumentar a riqueza de uma comunidade, além de promover a cultura da 
inovação e da competitividade nas empresas associadas. Nos itens a seguir, são apresentadas informações sobre o advento e o desenvolvimento dos parques tecnológicos.

\subsubsection{Origem E Evolução Dos Parques Tecnológicos}

Zouain (2003) afirma que o advento dos parques tecnológicos se deu entre os anos 1960 e 1970, principalmente nos Estados Unidos e Inglaterra. A iniciativa pioneira emergiu no âmbito da Universidade de Stanford, culminando, mais tarde, na criação do Vale do Silício, espaço de referência global em P\&D e criação de tecnologia (ANPROTEC, 2016a). Sua constituição se deu num ambiente de compartilhamento de experiências, endossadas por pesquisadores reconhecidos e capitalistas que investiram em pesquisas inovadoras, criando um contexto favorável ao desenvolvimento tecnológico na Califórnia.

Desde 1960, os parques vêm se constituindo como espaços de referência em atividades inovativas, a partir da colaboração entre os atores-chave para seu desenvolvimento, como universidades, institutos de pesquisa e empresas de base tecnológica (Pessôa et al. 2012). Segundo Claver-Cortés, Marco-Lajara, Manresa-Marhuenda e García-Lillo (2017), o ambiente comum aos parques tecnológicos de sucesso é formado pela constante interação entre os agentes, além do compartilhamento de uma linguagem, regras e valores em comum.

A ANPROTEC (2016b) comenta que a demanda dos empreendedores está crescendo e que um único espaço de apoio já não é suficiente, fazendo com que surjam ambientes formados por áreas de inovação (parques científicos e tecnológicos, cidades inteligentes, clusters, distritos de inovação, comunidades de inovação e outras áreas de inovação) e por mecanismos de inovação (incubadoras de empresas, aceleradoras, coworkings, living labs e outros).

\subsubsection{Características Dos Parques Tecnológicos}

Zouain (2003) e a ANPROTEC (2016a) abordam as principais características dos parques tecnológicos, com destaque para as seguintes: a) são ambientes promovidos e/ou vinculados às universidades, fazendo uso das pesquisas desenvolvidas por elas; b) fazem parte de setores da economia relacionados à alta tecnologia; c) promovem a criação de novas empresas de base tecnológica, a partir das incubadoras, como as spin-offs (criadas pelas universidades) ou ainda as empresas próprias do parque; d) concentram-se nas atividades de $\mathrm{P} \& \mathrm{D}$, por intermédio dos laboratórios das empresas participantes; e) promove a gestão da propriedade intelectual; f) estabelecem relações internacionais com investidores de risco.

O propósito básico das organizações constituintes dos parques tecnológicos é a criação de novos produtos, a partir de atividades de base tecnológica de pesquisa e desenvolvimento (Zhang, 2005). Já Chen et al. (2014) vão além, afirmando que os parques tecnológicos são motores do desenvolvimento econômico e uma fonte de capital intelectual.

Zouain e Plonski (2015) trazem uma contribuição interessante para a compreensão da relevância dos parques tecnológicos. Os autores os consideram como agentes do desenvolvimento urbano sustentável, devido às atividades de atração, acolhimento e treinamento de pesquisadores, que, ao desenvolverem pesquisas, transformam os parques tecnológicos em verdadeiros sistemas regionais de inovação. Os autores também afirmam que o processo de implantação dos parques leva em consideração, além do bem-estar dos seus 
membros, a criação de benefícios para as comunidades circunvizinhas ao parque, exercendo seu compromisso social para com elas.

As características geográficas dos parques tecnológicos também se constituem como uma importante variável para sua legitimação. Estarem situados em torno das universidades e seus pesquisadores, organizações, investidores, clientes e fornecedores possibilita aos parques tecnológicos oferecerem às empresas de base tecnológica o suporte necessário para seu desenvolvimento (Löfsten \& Lindelöf, 2005).

Claver-Cortés et al. (2017) também compartilham a concepção de que a localização de um parque tecnológico tem efeito positivo na inovação, visto que os fluxos de conhecimento circulam nas proximidades desses parques. Um outro desdobramento dessa integração entre os parques tecnológicos e as universidades e centros de pesquisa é o fomento às transformações nos cursos oferecidos por essas instituições, melhorando a qualidade das capacitações disponibilizadas aos empreendedores (Zouain \& Plonski, 2015).

Diversas são as formas jurídicas que os parques tecnológicos estão aptos a assumir: eles podem ser públicos, privados, com ou sem fins lucrativos, constituídos como sociedades de economia mista, fundações, Organizações da Sociedade Civil de Interesse Público (OSCIPs) ou podem estar ligados à administração direta. Pessôa et al. (2012) ponderam que as diferentes formas jurídicas e, por conseguinte, de gestão dos parques, podem influenciar nas condições oferecidas às atividades inovativas.

\section{Metodologia}

Esta pesquisa é classificada como descritiva, ao delinear e caracterizar as ações inovativas presentes nos Parques Tecnológicos do Nordeste. A abordagem de pesquisa adotada é mista (qualitativa e quantitativa), que, de acordo com Creswell (2010), permite a utilização dos pontos fortes de ambas as abordagens, obtendo-se insights mais profundos.

Em relação aos critérios para seleção dos objetos de análise, busca-se contribuir para a caracterização das ações inovativas dos parques tecnológicos instalados no Nordeste, que, de acordo com a ANPROTEC (2016a), ainda são minoria, quando comparados com os das demais regiões brasileiras.

Tais caracterização e comparação podem trazer insights sobre o perfil e o nível de desenvolvimento das atividades exercidas nos estados nordestinos, assim, houve a seleção da população de forma intencional. Segundo o Ministério da Ciência, Tecnologia, Inovações e Comunicações, três estados - Maranhão, Rio Grande do Norte e Piauí - não possuem iniciativas de parques em nenhum estágio de desenvolvimento, apesar de contarem com as condições necessárias para viabilizar o empreendimento (Ministério da Ciência, Tecnologia, Inovações e Comunicações, 2014).

O Nordeste possui sete parques tecnológicos, localizados em Alagoas (Parque Tecnológico de Alagoas); Bahia (Tecnovia); Ceará (Padetec); Paraíba (PaqTcPB); Pernambuco (Porto Digital e PARQTEL) e Sergipe (SergipeTec). Esta pesquisa é composta por cinco desses parques. Entre os não abordados, tem-se o PARQTEL, localizado em Recife, que tem o objetivo de ser um concentrador de inovação a partir de uma incubadora de projetos e não de empresas, o que, para o representante contatado, tornava impraticável responder aos questionamentos. Quanto ao Padetec, localizado em Fortaleza, o responsável afirmou que, apesar da denominação de parque tecnológico, este é, na verdade, uma incubadora de empresas, que passa pela avaliação da proposta de ser transformada em parque tecnológico. 
Neste estudo, foram utilizados como fonte primária e instrumento de coleta de dados questionários semiestruturados online da plataforma Google Forms, aplicados junto aos representantes legais dos parques tecnológicos nordestinos, que responderam questões subjetivas em relação às ações inovativas dos parques, a exemplo do impacto das inovações tecnológicas. Quantitativamente, submeteram respostas sobre estrutura dos parques, tipos de inovação e resultados alcançados pela introdução da inovação nos negócios. O questionário foi adaptado de Correia (2010), que, em sua pesquisa, também abordou parques tecnológicos. Entre as fontes secundárias de dados, há os relatórios da ANTROPEC (2016a, 2016b).

Para efeito de tratamento e análise dos dados da presente pesquisa, executa-se a tabulação dos questionários semiestruturados por meio do software Excel ${ }^{\circledR}$ para Windows versão 2013. Tanto as respostas das perguntas de múltipla escolha quanto as das perguntas abertas foram apresentadas resumidamente no decorrer da análise dos resultados, levando-se em consideração os pontos pertinentes e comparando-os com a literatura sobre a temática.

A partir dos objetivos e do instrumento de coleta de informações são apresentadas, no Quadro 1, as categorias analíticas e os elementos de análise, que serviram de base para as comparações das atividades inovativas dos casos.

Quadro 1 - Categorias analíticas e elementos de análise

\begin{tabular}{|c|l|}
\hline \multicolumn{1}{|c|}{ Categorias analíticas } & \multicolumn{1}{c|}{ Elementos/índices de análise } \\
\hline \multirow{3}{*}{ Características do Parque Tecnológico } & Localização; \\
& Instituição gestora; \\
& Natureza e forma jurídica; \\
& Áreas de atuação; \\
& Quantitativo de empresas e colaboradores ativos. \\
\hline & Tipos; \\
& Relevância no mercado nacional; \\
& P\&D; \\
& Introdução de produto novo ou significativamente aperfeiçoado; \\
& Relações entre os parques tecnológicos e as universidades; \\
& Impacto das inovações; \\
& Resultados alcançados com as inovações; \\
& Problemas e obstáculos às atividades inovativas. \\
\hline
\end{tabular}

Fonte: adaptado de Correia (2010).

\section{Resultados e Discussão}

Esta seção traz os resultados obtidos na realização da pesquisa. Assim, para melhor compreensão, esta foi subdividida de acordo com os cinco parques tecnológicos estudados.

\subsection{Parque Tecnológico de Alagoas}

Este parque foi instituído pelo governo do Estado por meio do decreto 33.965/2014, visando a fomentar o desenvolvimento econômico e social por intermédio de incentivos à geração de negócios inovadores. A instituição é formada pelo Polo de Tecnologia da Informação, Comunicação e de Arapiraca/AL (Parque Tecnológico de Alagoas, n.d.).

O parque está situado em Maceió e possui natureza jurídica pública. Além disso, está sob a forma jurídica de fundação. Com atividades iniciadas recentemente, em 08 de agosto de 
2014, atua nas áreas de agronegócios, mídia e áudio visual, tecnologia da informação e comunicação e serviços e conta com 5 pessoas na administração e 9 indivíduos no apoio. Já com relação à quantidade de empresas incubadas ou instaladas, o respondente afirmou que o parque está em fase de prospecção de empresas.

Provavelmente, devido ao recente início de suas atividades, o Parque Tecnológico de Alagoas possui estrutura limitada, entre eles laboratórios e equipamentos disponíveis às empresas incubadas e um centro de eventos e treinamento. Estão em fase de construção/implementação, a incubadora, o centro de $\mathrm{P} \& \mathrm{D}$ pública, mecanismos de transferência de tecnologia, integração entre as empresas do parque e centros de $\mathrm{P} \& \mathrm{D}$ ou universidades e os ambiente de serviços. Ademais, foi citado que estão em base de implantação um coworking e uma biblioteca.

\subsection{Parque Tecnológico da Bahia}

O Parque Tecnológico da Bahia, também conhecido como Tecnovia, localiza-se na cidade de Salvador e teve suas atividades iniciadas em 12 de setembro de 2012, sob a natureza jurídica pública e a forma de sociedade anônima.

Essa instituição permite que o setor empresarial, o governo e a comunidade acadêmica trabalhem juntos com o intuito de desenvolver produtos e serviços que tenham impactos positivos e relevantes na região. Assim, para que isto ocorra, possui uma estrutura que se divide em três eixos fundamentais: eixo da inovação, eixo da tecnologia e eixo da ciência (Parque Tecnológico da Bahia, n.d.).

O Tecnovia insere-se nas áreas de atuação relacionadas à biotecnologia, construção civil, engenharias, energia e tecnologia da informação e comunicação, e possuía, em 2017, 34 empresas incubadas ou instaladas. Com relação à equipe administrativa, esta é formada por 15 pessoas, além de possuir 3 colaboradores que executam atividades de apoio ao parque, como bolsistas, estagiários e secretariado.

No parque, existe a seguinte estrutura: a) centro de $\mathrm{P} \& \mathrm{D}$ público; b) laboratórios ou equipamentos disponíveis às empresas incubadas; c) ambiente de serviços que abrigam bancos, restaurantes, entre outros. Pode-se notar que incubadora, centro de eventos e treinamentos, dentre outros elementos, são ausentes.

\subsection{Fundação Parque Tecnológico da Paraíba}

O Parque Tecnológico da Paraíba (PaqTcPB) tem como objetivo fomentar o desenvolvimento de projetos de ensino, pesquisa e extensão, disponibilizando apoio administrativo (PaqTcPB, n.d.).

As informações referentes ao Parque Tecnológico da Paraíba foram fornecidas pela gerente de inovação da instituição. Este empreendimento, situado em Campina Grande, iniciou suas atividades em 28 de dezembro de 1984. A natureza jurídica do PaqTcPB é organização social, considerada por Pessôa et al. (2012) a mais adequada aos propósitos deste tipo de organização, pois permite que os parques não se sujeitem aos controles e limitações da atividade pública, ao tempo em que desfrutam os benefícios das demais entidades sem fins lucrativos. A sua forma jurídica é classificada como fundação, que, para os autores anteriormente citados, apresenta como vantagem uma série de isenções de impostos e contribuições. 
Esse parque possui como áreas de atuação: biotecnologia, agronegócios, eletrônica, energia, mídia e audiovisual, meio ambiente, petróleo e derivados, tecnologia da informação e economia criativa. Em 2017, havia 25 empresas incubadas ou instaladas. Para que suas atividades transcorram da melhor forma possível, 26 pessoas trabalham na administração, que conta ainda com 9 colaboradores de apoio (estagiários, bolsistas e secretário).

Estão presentes no PaqTcPB os seguintes itens estruturais: a) incubadora; b) centro de P\&D público; c) laboratórios ou equipamentos disponíveis às empresas incubadas; d) mecanismos de transferência de tecnologia; e) mecanismos ou sistemas que promovam a integração de ações entre as empresas do parque e entre essas e centros de P\&D ou universidades; f) ambiente de serviços que abrigue bancos, restaurantes, entre outros; g) centro de eventos e treinamentos; e h) área de esporte e lazer. Nesse cenário, pode-se perceber que o PaqTcPB possui todas as estruturas/mecanismos inclusos no questionário. $\mathrm{O}$ parque conta, ainda, com o "Centro de Inovação Tecnológica Telmo Araújo", que serve de apoio para as atividades das empresas associadas.

\subsection{Porto Digital}

O Porto Digital é um dos principais ambientes de inovação do Brasil, apresentando como missão ser um dos principais pilares da economia no futuro de Pernambuco, além de uma das âncoras do desenvolvimento sustentável desse Estado (Porto Digital, n.d.).

O Porto Digital está localizado numa região estratégica para suas atividades. Grande parte de seu território fica no centro da região metropolitana de Recife, próximo a aeroporto, edifícios empresariais que abrigam suas empresas de tecnologia, bancos, órgãos públicos e governamentais, shopping, cartórios, escritórios de advocacia, contabilidade, agências de publicidade, assessorias de marketing e comunicação, centros de capacitação, restaurantes, cinema, teatro e institutos de artes (Porto Digital, n.d.).

A instituição enquadra-se como organização social privada sem fins lucrativos e iniciou suas atividades em 12 de dezembro de 2000 em Recife. Possuía, em 2017, 278 empresas instaladas ou incubadas, que atuam nas áreas de mídia e audiovisual, tecnologia da informação e comunicação, economia criativa (design, fotografia, cine-vídeo-animação, jogos digitais e músicas). Para a execução de suas atividades, conta com 55 pessoas trabalhando na administração e 19 no apoio (estagiários, bolsistas e secretário). Zouain e Plonski (2015) apontam que, do ponto de vista econômico, a contribuição do Porto Digital atingiu 3,5\% do Produto Bruto do Estado em apenas alguns anos de operação.

O Porto Digital conta com incubadora, laboratórios e equipamentos disponíveis às empresas incubadas, mecanismos de transferência de tecnologia, sistema de promoção à integração de ações entre as empresas do parque e centros de $\mathrm{P} \& \mathrm{D}$ ou universidades, ambiente de serviços que abriga bancos, restaurantes, entre outros; centro de eventos e treinamentos e área de esporte e lazer. O parque tinha ainda, em 2017, 31 centros empresariais em operação, 2 aceleradoras e 4 espaços de coworking. Além disso, O Porto Digital expandiu suas atividades para o agreste de Pernambuco em 2014, onde opera, em Caruaru, o Armazém da Criatividade, localizado no Polo da Moda da cidade, apoiando a cadeia da moda e áreas como design e games, além dos setores de tecnologia da informação. 


\subsection{Sergipe Parque Tecnológico}

O SergipeTec objetiva a promoção do desenvolvimento científico e tecnológico local e regional e possui a missão de promover a inovação tecnológica para o desenvolvimento de Sergipe, por meio da gestão sistêmica de suas áreas de atuação, integrando os setores: Estado, escola e empresa. O parque tem como valores o humanismo, a integridade, a inovação, a perseverança, o trabalho em equipe e o empenho (SergipeTec, n.d.).

O parque está localizado na cidade de São Cristóvão e iniciou suas atividades em 20 de julho de 2004, focando nas seguintes áreas de atuação: biotecnologia, energia, meio ambiente, tecnologia da informação e comunicação. Caracteriza-se como uma associação privada (com capital para lançamento e desenvolvimento oriundo de entidades privadas), sem fins lucrativos sob a forma jurídica de associação. Está localizado em terreno cedido pela Universidade Federal de Sergipe (UFS), com 130 mil m² $^{2}$ de extensão.

Concernente à equipe de trabalho, é formada (à época da pesquisa), por 18 funcionários atuantes na administração, além dos 7 que trabalham no apoio. Quando questionado sobre as estruturas presentes no parque, o respondente elencou incubadora, laboratórios ou equipamentos disponíveis às empresas incubadas e área de esporte e lazer. Além disso, a instituição também conta com o Centro Vocacional Tecnológico. Ademais, estão em fase de construção/implementação de mecanismos de promoção da integração entre o parque e centros de P\&D ou universidades, ambiente de serviços que abrigue bancos, restaurantes, centro de eventos e treinamentos.

\subsection{Impactos das Atividades Inovativas dos Parques Nordestinos}

Neste item, objetiva-se comparar as atividades inovativas dos diferentes parques tecnológicos da região Nordeste.

Zhang (2005) pontua que a finalidade das organizações que fazem parte dos parques tecnológicos é a criação de novos produtos por meio de atividades de base tecnológica. $\mathrm{O}$ Quadro 2 demonstra a introdução de um produto (bem ou serviço) novo ou significativamente aperfeiçoado no mercado nacional pelas empresas presentes nos parques tecnológicos.

No Parque Tecnológico de Alagoas, que está em fase de prospecção de empresas, não houve produtos lançados ou melhorados. Todavia, somente os Parques Tecnológicos da Paraíba e da Bahia afirmam que a importância da atividade de P\&D é alta. O Porto Digital e o SergipeTec acreditam que é média.

Quadro 2 - Introdução de produto novo ou significativamente aperfeiçoado

\begin{tabular}{|l|c|c|c|c|}
\hline \multicolumn{1}{|c|}{ Aspectos Analisados } & $\begin{array}{c}\text { Tecnovia } \\
\text { (BA) }\end{array}$ & $\begin{array}{c}\text { PaqTcPB } \\
\text { (PB) }\end{array}$ & $\begin{array}{c}\text { Porto } \\
\text { Digital } \\
\text { (PE) }\end{array}$ & $\begin{array}{c}\text { SergipeTec } \\
\text { (SE) }\end{array}$ \\
\hline $\begin{array}{l}\text { Introdução de produto (bem ou serviço) novo no } \\
\text { mercado nacional }\end{array}$ & Sim & Sim & Sim & Sim \\
\hline $\begin{array}{l}\text { Introdução de produto (bem ou serviço) } \\
\text { significativamente aperfeiçoado(s) para o mercado } \\
\text { nacional }\end{array}$ & Sim & Sim & Sim & Sim \\
\hline Importância da atividade de P\&D & Alta & Alta & Média & Média \\
\hline
\end{tabular}

Fonte: elaborado pelos autores (2017). 
O respondente do Tecnovia, de Salvador, citou o 'Meu remédio', um aplicativo mobile que permite encontrar em apenas 3 passos os medicamentos disponíveis nos Postos de Saúde do município em que reside.

Alguns exemplos de produtos novos ou significativamente aperfeiçoados do Parque Tecnológico da Paraíba relatados pela respondente foram: a) plataforma web e mobile, que possibilita aos pais de alunos do Fundamental I e II acompanharem todo o desenvolvimento acadêmico dos filhos, comunicar-se de forma direta com os professores e obter informações que auxiliem no aprendizado; b) O "DitanGo", que gera áudio de alta qualidade em mais de 40 idiomas a partir de documentos nos formatos PDF, DOC e texto; c) "Knowbook", plataforma que facilita a organização, o armazenamento e o compartilhamento de conteúdos educacionais, funcionando como uma rede social colaborativa; d) produção de jogos eletrônicos que fomentam educação, ciência e cultura, por meio do desenvolvimento de tecnologias e metodologias inovadoras baseadas em jogos digitais, gamificação e imersão.

O respondente do Porto Digital expôs alguns dos produtos novos ou significativamente melhorados: a) um serviço de geolocalização - tecnologia eleita a mais precisa do mercado pela Microsoft, ACM e IEEE; b) serviços de gerenciamento da segurança em regime 24x7 x365 (sem interrupções) e soluções inovadoras de segurança em nuvem via modelo de SaaS (Software as a Service); c) O Livox, primeiro software do mundo de comunicação alternativa e aumentativa para tablets em português, com o diferencial de ser uma ferramenta multimídia que possibilita sua utilização em qualquer ambiente; e d) desenvolvimento de soluções avançadas para a automação de todo o ciclo de decisão em operações de crédito, cobrança, risco e fraude.

O respondente do SergipeTec citou os seguintes produtos novos ou significativamente melhorados: a) um app para desenvolvimento de atividades físicas; b) sistema de comércio eletrônico; e c) regulador do sistema de saúde.

Oportuno resgatar, neste ponto, as considerações de Desidério (2016) acerca das áreas promissoras para abrir um negócio do futuro (fabricação de drones, realidade virtual, inteligência artificial, tecnologia e análise de alimentos, leitura biométrica, detecção de fraude, bem-estar corporativo e materiais de construção sustentáveis). Percebe-se que os parques tecnológicos nordestinos, a partir do que foi relatado pelos participantes da pesquisa, ainda se concentram em áreas pouco disruptivas, com atuação em tecnologia da informação básica.

É importante relatar que a difusão da tecnologia orientada a tornar a inovação cotidiana para as pessoas envolve a influência de vários processos sociais (Tola \& Contini, 2015). Assim, a capacidade de transferência de tecnologia indica o nível de avanço tecnológico das organizações que residem nos parques (Goraczkowska, 2014). Corroborando tal perspectiva, um dos aspectos citados no conceito de parques tecnológicos é a "transferência de conhecimento e tecnologia, com o objetivo de incrementar a produção de riqueza de uma região" (ANPROTEC, 2016a, p. 11). Todavia, apenas o Parque Tecnológico da Bahia e o Porto Digital possuem mecanismos de transferência de tecnologia. Nesse cenário, o Quadro 3 apresenta algumas relações entre os parques tecnológicos e as universidades.

O Quadro 3 demonstra que grande parte dos parques tecnológicos abordados possuem um vínculo formal com universidades e centros de pesquisa. Entretanto, 3 deles (Parques Tecnológicos da Bahia e de Alagoas e o Porto Digital) não estão localizados próximos às universidades. 
Quadro 3 - Relações entre os parques tecnológicos e as universidades

\begin{tabular}{|l|c|c|c|c|c|}
\hline \multicolumn{1}{|c|}{ Aspectos Analisados } & $\begin{array}{c}\text { Parque Tec. } \\
\text { de Alagoas } \\
\text { (AL) }\end{array}$ & $\begin{array}{c}\text { Tecnovia } \\
\text { (BA) }\end{array}$ & $\begin{array}{c}\text { PaqTcPB } \\
\text { (PB) }\end{array}$ & $\begin{array}{c}\text { Porto } \\
\text { Digital } \\
\text { (PE) }\end{array}$ & $\begin{array}{c}\text { SergipeTec } \\
\text { (SE) }\end{array}$ \\
\hline $\begin{array}{l}\text { Vínculo com universidades/centro de } \\
\text { pesquisa }\end{array}$ & Formal & Formal & Formal & Informal & Formal \\
\hline $\begin{array}{l}\text { O parque está localizado próximo à } \\
\text { universidade }\end{array}$ & Não & Não & Sim & Não & Sim \\
\hline $\begin{array}{l}\text { A proximidade da universidade } \\
\text { facilita a criação e o } \\
\text { compartilhamento de conhecimento }\end{array}$ & Sim & Sim & Sim & Sim & Sim \\
\hline
\end{tabular}

Fonte: elaborado pelos autores (2017).

Aqueles que responderam de modo afirmativo quanto à proximidade, relataram que isso facilita a criação e o compartilhamento de conhecimento, o que ratifica os comentários de Chen et al. (2014) e Farré-Perdiger et al. (2016), que discorrem que é por meio das interações entre universidade, parques tecnológicos e empresas que surgem as inovações. Já Löfsten e Lindelöf (2005) afirmam a importância das características geográficas como uma variável para a legitimação dos parques tecnológicos. Claver-Cortés et al. (2017) concordam com os autores anteriormente citados e afirmam que a localização dos parques tem um efeito positivo para a geração de inovação. Todavia, tal aspecto não demonstrou ser de grande importância para o Porto Digital, o maior parque do Nordeste, já que não apresenta vínculo formal com universidades e nem está localizado próximo a uma.

O Quadro 4 apresenta a importância de determinadas consequências das atividades inovativas.

Quadro 4 - Impacto das atividades inovativas

\begin{tabular}{|l|c|c|c|c|}
\hline \multicolumn{1}{|c|}{ Aspectos Analisados } & $\begin{array}{c}\text { Tecnovia } \\
\text { (BA) }\end{array}$ & $\begin{array}{c}\text { Parque } \\
\text { Tec. da } \\
\text { Paraíba }\end{array}$ & $\begin{array}{c}\text { Porto } \\
\text { Digital }\end{array}$ & $\begin{array}{c}\text { Parque } \\
\text { Tec. de } \\
\text { Sergipe }\end{array}$ \\
\hline Melhoria da qualidade dos bens ou serviços & Média & Alta & Alta & Alta \\
\hline Ampliação da gama de produtos ou serviços ofertados & Média & Média & Alta & Média \\
\hline $\begin{array}{l}\text { Permitir manter a participação de mercado das } \\
\text { empresas incubadas ou instaladas no parque }\end{array}$ & Baixa & Média & Média & Alta \\
\hline $\begin{array}{l}\text { Ampliação da participação de mercado das empresas } \\
\text { incubadas ou instaladas no parque }\end{array}$ & Baixa & Média & Média & Média \\
\hline Permitir abrir novos mercados & Baixa & Alta & Baixa & Baixa \\
\hline $\begin{array}{l}\text { Aumento da capacidade de produção ou de prestação } \\
\text { de serviços }\end{array}$ & Não sei & Alta & Média & Média \\
\hline $\begin{array}{l}\text { Redução dos custos de produção ou dos serviços } \\
\text { prestados }\end{array}$ & Não sei & Alta & Baixa & Média \\
\hline Redução dos impactos ao meio ambiente & Não sei & Alta & Não sei & Média \\
\hline $\begin{array}{l}\text { Permitir o controle de aspectos ligados à saúde e } \\
\text { segurança }\end{array}$ & Não sei & Alta & Alta & Alta \\
\hline Fona
\end{tabular}

Fonte: elaborado pelos autores (2017). 
Como demonstrado no Quadro 4, os diversos impactos das atividades inovativas variam bastante a depender do parque em questão e do aspecto analisado. A melhoria da qualidade dos bens e serviços, ampliação da gama de produtos ou serviços ofertados, o controle de aspectos ligados à saúde e segurança e a participação de mercado das empresas incubadas ou instaladas nos parques foram os indicadores que apresentaram maior importância para a amostra. O respondente do Parque Tecnológico de Alagoas relatou que não sabia as respostas para esses questionamentos, devido ao motivo já relatado neste estudo.

O Quadro 5 traz os fatores prejudiciais às atividades inovativas das empresas incubadas/instaladas. Os de maior importância relatados pelos respondentes foram: falta de informação sobre os mercados, riscos econômicos excessivos, elevados custos de inovação, falta de pessoal qualificado, escassez de fontes apropriadas de financiamento e rigidez organizacional. Mais uma vez, não foi possível perceber a consideração de tais fatores pelo Parque Tecnológico de Alagoas.

\section{Quadro 5 - Importância dos fatores prejudiciais às atividades inovativas das empresas} incubadas/instaladas

\begin{tabular}{|l|c|c|c|c|}
\hline $\begin{array}{c}\text { Fatores que podem prejudicar as atividades } \\
\text { inovativas das empresas incubadas ou instaladas }\end{array}$ & $\begin{array}{c}\text { Tecnovia } \\
(\mathbf{B A})\end{array}$ & $\begin{array}{c}\text { PaqTcPB } \\
\text { (PB) }\end{array}$ & $\begin{array}{c}\text { Porto } \\
\text { Digital } \\
\text { (PE) }\end{array}$ & $\begin{array}{c}\text { SergipeTec } \\
\text { (SE) }\end{array}$ \\
\hline Riscos econômicos excessivos & Não sei & Média & Média & Alta \\
\hline Elevados custos de inovação & Não sei & Média & Média & Alta \\
\hline Escassez de fontes apropriadas de financiamento & Não sei & Média & Média & Média \\
\hline Rigidez organizacional & Não sei & Média & Média & Média \\
\hline Falta de pessoal qualificado & Média & Alta & Baixa & Média \\
\hline Falta de informação sobre mercados & Não sei & Alta & Média & Alta \\
\hline $\begin{array}{l}\text { Dificuldade para se adequar a padrões, normas ou } \\
\text { regulamentações }\end{array}$ & Baixa & Média & Não sei & Média \\
\hline $\begin{array}{l}\text { Fraca resposta dos consumidores quanto aos novos } \\
\text { produtos }\end{array}$ & Não sei & Média & Baixa & Alta \\
\hline
\end{tabular}

Fonte: elaborado pelos autores (2017).

Tal informação apresenta semelhanças com o resultado encontrado pelo estudo do IBGE (2016), que evidenciou as dificuldades relacionadas aos elevados custos de se inovar, a escassez de fontes apropriadas de financiamento e pelos riscos econômicos excessivos. Essa fonte também demonstrou que a depender do setor de atuação da empresa - indústria, eletricidade e gás e serviços selecionados -, os fatores apresentam impactos/importâncias diferentes.

\section{Considerações Finais}

Os resultados deste estudo oportunizaram conhecer as principais características e o impacto das atividades inovativas dos parques tecnológicos do Nordeste brasileiro. Percebeuse, de modo geral, que as iniciativas têm demonstrado esforços para desenvolver sua atuação em cada Estado. No entanto, há determinados aspectos ainda em fase embrionária. 
O Parque Tecnológico de Alagoas, de recente inauguração, de fato apresenta atividades iniciais de atuação, a exemplo da prospecção de empresas. No Tecnovia (BA), foram relatados poucos novos produtos, bem como desconhecimento de vários aspectos que, de acordo com a literatura, exercem interferência nas atividades inerentes aos parques tecnológicos. No entanto, a presença de transferência tecnológica no Tecnovia é um ponto positivo. O SergipeTec, que atua com sistemas voltados à saúde e comércio, ainda implementa alguns mecanismos essenciais ao parque, como agência bancária, restaurantes, centro de eventos e treinamentos.

O destaque fica para os parques da Paraíba e de Pernambuco. No PaqTcPB, que desenvolve ferramentas tecnológicas para educação, vários novos produtos foram relatados, inclusive com base em gamificação, alternativa de ensino-aprendizagem que tem despertado grande interesse. Além disso, o parque conta com os principais elementos estruturais investigados neste trabalho, além de possuir relações institucionalizadas com universidades e considerar, em termos de gestão, os elementos que impactam as atividades inovativas. Quanto ao Porto Digital, tem suas atividades inovativas bem desenvolvidas, contando com ampla estrutura física e administrativa de apoio às empresas associadas, bem como um extenso e diverso portfólio de produtos lançados. Fato que chama a atenção é que o Porto Digital, tendo vínculo apenas informal com universidades e não estando próximo a elas, mantém seus mecanismos de transferência tecnológica, provavelmente, de forma direta com o mercado.

Quanto à estrutura dos parques, também foi observada melhor adequação do PaqTcPB e Porto Digital, que contam com ferramentas e espaços de incentivo à inovação. Tendo em vista a observação da ANPROTEC (2016b) quanto à necessidade de ambientes e mecanismos de inovação, os demais parques apresentam carências que, em determinados tempo e situação, podem interferir na execução de suas atividades inovativas.

Concernente ao impacto das atividades inovativas, não foi possível analisar a situação do Parque Tecnológico de Alagoas, o qual o participante da pesquisa não respondeu aos itens. No Tecnovia, apenas os itens "melhoria da qualidade dos bens ou serviços" e "ampliação da gama de produtos ou serviços ofertados" foram considerados de média importância. Nos demais parques, a maioria dos impactos das atividades inovativas foram considerados de média e alta importância, com exceção da "abertura de novos mercados", que foi considerado de baixa importância pelo Porto Digital e SergipeTec e "redução dos custos de produção ou dos serviços prestados", de baixa relevância segundo o Porto Digital.

Este artigo não intenta apresentar um perfil último dos parques tecnológicos nordestinos. Além disso, possui limitações quanto ao número de parques abordados, uma vez que dois dos sete parques da região não puderam ser avaliados. Como proposição para pesquisas futuras, sugere-se uma nova investigação dos parques nordestinos, acompanhando também os aqui não abordados e possíveis novos parques. Além disso, pode-se traçar a trajetória dos cinco parques analisados neste trabalho, a partir de uma perspectiva longitudinal.

\section{REFERÊNCIAS}

Akhmetzianov, T. R., \& Kosachev, V. I. (2016). Forecasting of innovative activity dynamics using industry competition indicators analysis (Evidence from food industry of Russia). Procedia Economics and Finance, 39, 746-752. 
Albahari, A., Pérez-Canto, S., Barge-Gil, A., \& Modrego, A. (2017). Technology Parks versus Science Parks: does the university make the difference?. Technological Forecasting and Social Change, 116, 13-28.

Associação Nacional de Entidades Promotoras de Empreendimentos Inovadores. (2016). Dos Parques Científicos e Tecnológicos aos ecossistemas de inovação. 1-26.

Associação Nacional de Entidades Promotoras de Empreendimentos Inovadores. (2016). Mecanismos da Geração de Empreendimentos Inovadores: mudança na organização e na dinâmica dos ambientes e o surgimento de novos atores. 1-28.

Bagheri, S. K., Eshtehardi, M. S. A., \& Goodarzi, M. (2015). Innovative activities in Iran: A first glance. World Patent Information, 42, 28-34.

Chen, M., Wang, H., Chang, Y., \& Hung A. (2014). Knowledge sharing, social capital and firm performance in technological clusters of Taiwan Science Parks: an innovation strategy perspective. Anais do PICMET. Portland, EUA.

Claver-Cortés, E., Marco-Lajara, B., Manresa-Marhuenda E., \& García-Lillo, F. (2017). Location in scientific-technological parks, dynamic capabilities, and innovation. Technology Analysis \& Strategic Management. 1-14.

Correia, A. M. M. (2010). Potencialidades e limites para o desenvolvimento econômico e inovativo local: uma análise comparativa em parques tecnológicos da região Nordeste. Dissertação, Universidade Federal da Paraíba, João Pessoa, PB, Brasil.

Creswell, J. W. (2010) Projeto de pesquisa: métodos qualitativo, quantitativo e misto. (3a ed.). Porto Alegre: Artmed.

De-Carli, E., Segatto, A. P., Alves, F. S., \& Kuribara, F. M. (2017). Characterization on the patents deposits from Brazil's Public Research Institutes 2004-2013. RAI, 14(2), 168-177.

Desidério, M. (2016). 8 áreas promissoras para abrir um negócio do futuro. 2016. Recuperado em: 17 de junho de 2017, de http://abr.ai/2FEZ4Pc.

Farré-Perdiguer, M., Sala-Rios, M., \& Torres-Solé, T. (2016). Network analysis for the study of technological collaboration in spaces for innovation. Science and technology parks and their relationship with the university. International Journal of Educational Technology in Higher Education, 13(1), 8.

Glebova, I., Yasnitskaya, Y., \& Maklakova, N. (2015). The Evaluation of the Innovative Activity of Modern Russia's Higher Educational Establishments and Ways of its Fostering. Procedia-Social and Behavioral Sciences, 191, 2374-2381.

Goraczkowska, J. (2014). Technological parks and the innovation activity of enterprises in the industrial networks-developed regions vs. the intermediate ones. Quarterly Journal of Economics and Economic Policy, 10, (2), 137-156.

Guadix, J., Carrillo-Castrillo, J., Onieva, L., \& Navascués, J. (2016). Success variables in science and technology parks. Journal of Business Research, 69, (11), 4870-4875. 
International Association of Science Parks. (2017). The Role of STPs and areas of innovation. Recuperado em 25 de julho de 2017, de http://bit.ly/2pk3EHE.

Instituto Brasileiro de Geografia e Estatística. (2016). PINTEC 2014. Brasília, 2014.

Kayalar, M., Çıta, K., Ergani, B., \& Aktekin, E. (2015). Determination of Innovative Activities in the Dried Fruit Exporter Companies: The Case of Aegean Region. Procedia-Social and Behavioral Sciences, 195, 1176-1185.

Löfsten, H., \& Lindelöf, P. (2005). R\&D networks and product innovation patterns: academic and non-academic new technology-based firms on Science Parks. Technovation, 25, 10251037.

Ministério da Ciência, Tecnologia, Inovações e Comunicações. Estudo de Projetos de Alta Complexidade: indicadores de parques tecnológicos/Centro de Apoio ao Desenvolvimento Tecnológico. Brasília: CDT/UnB.

Fundação Parque Tecnológico da Paraíba. (n.d.). O que fazemos? Recuperado em agosto de 2017, de http://www.paqtc.org.br/.

Parque Tecnológico Da Bahia. (n.d.). Institucional. Recuperado em agosto de 2017, de http://www.secti.ba.gov.br/parque/institucional/parque-tecnologico-da-bahia/.

Parque Tecnológico De Alagoas. (n.d.). Sobre o parque. Recuperado em agosto de 2017, de http://www.parquetecnologico.al.gov.br/about-us.

Pessôa, L. C., Cirani, C. B. S., Silva, M. M., \& Rangel, A. S. (2012). Parques Tecnológicos brasileiros: uma análise comparativa de modelos de gestão. RAI, São Paulo, 9(2), 253-273.

Porto Digital. (n.d.). Missão. Recuperado em agosto de 2017, de http://bit.ly/2HGQM66.

Schumpeter, J. A. (1961). Capitalismo, Socialismo e Democracia. Rio de Janeiro: Editora Fundo de Cultura.

Sergipe Parque Tecnológico. (n.d.). Apresentação Institucional. Recuperado em agosto de 2017, de http://sergipetec.org.br/apresentacao-institucional/.

Tola, A., \& Contini, M. V. (2015). From the diffusion of innovation to tech parks, business incubators as a model of economic development: the case of Sardegna Ricerche. ProcediaSocial and Behavioral Sciences, 176, 494-503.

Von Stamm, B. (2003). What are innovation, creativity and design. Management of Innovation, Design and Creativity (Cap. 1, pp. 1-18). Chichester: John Wiley \& Sons.

Zhang, Y. (2005). The Science Park phenomenon: development, evolution and typology. International Journal of Entrepreneurship and Innovation Management, 5,138-154.

Zouain, D. M., \& Plonski, G. A. (2015). Science and Technology Parks: laboratories of innovation for urban development - an approach from Brazil. Triple Helix, 2(1), 1-22.

Zouain, D. M. Parques Tecnólogicos: propondo um modelo conceitual para regiões urbanas O Parque Tecnólogico de São Paulo. (2003). Tese, Universidade de São Paulo, SP, Brasil. 